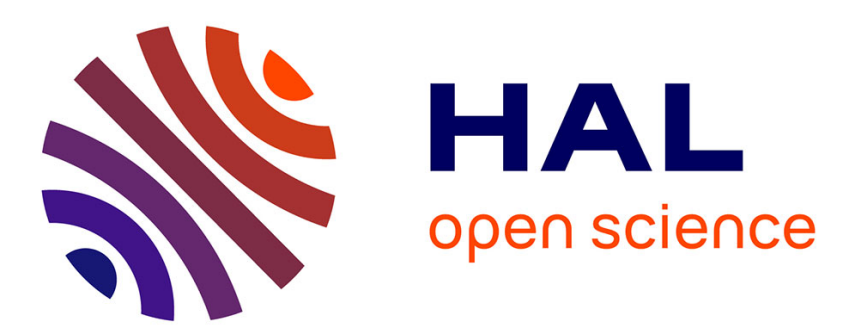

\title{
Prototype Combined Heater/Thermoelectric Power Generator for Remote Applications
}

Daniel Champier, C. Favarel, Jean-Pierre Bedecarrats, Tarik Kousksou, J. F

Rozis

\section{- To cite this version:}

Daniel Champier, C. Favarel, Jean-Pierre Bedecarrats, Tarik Kousksou, J. F Rozis. Prototype Combined Heater/Thermoelectric Power Generator for Remote Applications. Journal of Electronic Materials, 2013, 42 (7), pp.1888-1899. 10.1007/s11664-012-2459-x . hal-02014177

\section{HAL Id: hal-02014177 \\ https://hal.science/hal-02014177}

Submitted on 7 Nov 2019

HAL is a multi-disciplinary open access archive for the deposit and dissemination of scientific research documents, whether they are published or not. The documents may come from teaching and research institutions in France or abroad, or from public or private research centers.
L'archive ouverte pluridisciplinaire HAL, est destinée au dépôt et à la diffusion de documents scientifiques de niveau recherche, publiés ou non, émanant des établissements d'enseignement et de recherche français ou étrangers, des laboratoires publics ou privés. 


\title{
Prototype Combined Heater/Thermoelectric Power Generator for Remote Applications
}

5

\author{
D. CHAMPIER,${ }^{1,4}$ C. FAVAREL,${ }^{1,2}$ J. P. BÉDÉCARRATS, ${ }^{2}$ T. KOUSKSOU, ${ }^{1}$ \\ and J. F. ROZIS ${ }^{3}$
}

1.-Laboratoire des Sciences de l'Ingénieur Appliquées à la Mécanique et au Génie Electrique (SIAME), Univ Pau \& Pays Adour, Hélioparc 2, Avenue du Président Angot, 64053 Pau Cedex, France. 2.-LaTEP_EA 1932, Laboratoire de Thermique, Energétique et Procédés, ENSGTI, Univ Pau \& Pays Adour, Rue Jules Ferry, BP 7511, 64075 Pau, France. 3.-Planète Bois, 17 Route de Toulouse, 65690 Barbazan Debat, France. 4.—e-mail: daniel.champier@univ-pau.fr

This study presents a prototype thermoelectric generator (TEG) developed for remote applications in villages that are not connected to the electrical power grid. For ecological and economic reasons, there is growing interest in harvesting waste heat from biomass stoves to produce some electricity. Because regular maintenance is not required, TEGs are an attractive choice for smallscale power generation in inaccessible areas. The prototype developed in our laboratory is especially designed to be implemented in stoves that are also used for domestic hot water heating. The aim of this system is to provide a few watts to householders, so they have the ability to charge cellular phones and radios, and to get some light at night. A complete prototype TEG using commercial (bismuth telluride) thermoelectric modules has been built, including system integration with an electric DC/DC converter. The DC/DC converter has a maximum power point tracker (MPPT) driven by an MC9SO 8 microcontroller, which optimizes the electrical energy stored in a valve-regulated lead-acid battery. Physical models were used to study the behavior of the thermoelectric system and to optimize the performance of the MPPT. Experiments using a hot gas generator to simulate the exhaust of the combustion chamber of a stove are used to evaluate the system. Additionally, potential uses of such generators are presented.

Key words: Thermoelectric generator, maximum power point, MPPT, power generation, biomass stove

\section{INTRODUCTION}

According to the International Energy Agency, ${ }^{1,2}$ 1.4 billion people live without electricity, most of them in developing countries. They rely on biomass such as wood, charcoal, agricultural waste, and animal dung to meet their energy needs for cooking. Biomass is burned in an open fire, making an important contribution to household air pollution. According to the World Health Organization, use of wood fuel and dung for cooking and heating causes over 400,000 premature deaths in India annually,

\begin{tabular}{|l|lll|}
\hline Journal : 11664_JEM & Dispatch : 22-1-2013 & Pages : $\mathbf{1 2}$ \\
& & $\square$ LE & $\square$ TYPESET \\
& Article No.: 2459 & $\nabla$ CP & $\varnothing$ DISK \\
\hline
\end{tabular}

mostly women and children; For example, the concentration of airborne particulate matter in Indian household air using biomass is over $2000 \mu \mathrm{g}$ per cubic meter, compared with the US limit of $150 .^{3-6}$

To avoid this air pollution, the first thing to do is to use a stove instead of an open fire. To be efficient, stoves need tall flues to generate adequate draw. These flues are expensive and time-consuming to build. In some countries, with flat roofs, people do not have the technology to build chimneys going through the roof.

The possibility of adding an electric fan dramatically increases the widespread use of stoves. Addition of a fan greatly improves the overall performance of cooking stoves: it improves the air-to-fuel ratio, 
61 allowing far better combustion, and the total heat 62 recovery can be improved because the combustion 63 gases do not need to be at a high temperature.

64 Improving the efficiency and quality of combus65 tion contributes to reducing outside air pollution 66 and to reducing the quantity of wood used, which is 67 especially important in areas where wood is scarce.

68 When a household gains access to electricity, the 69 normal first use is as a kerosene or biomass sub70 stitute for lighting, extending working hours in the 71 evening or night. The other basic needs are mainly 72 radio and cellular phone charging (overall telephone 73 ownership in India reached $74 \%$ at the end of June

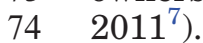

Connecting these households previously without electricity to the power grid would mean two important costs for remote villages: the cost of building new landlines and the cost of electricity distribution.

A study conducted by the International Bank for Reconstruction and Development ${ }^{8}$ shows that the cost of connecting houses to the grid in Bahia (Brazil) depends considerably on the distance of the village from the grid and on the number of utility poles per consumer, and also on the terrain (flat or hilly). The average cost of connecting households is more than US $\$ 300$, assuming one utility pole per consumer. The more scattered the households are (villages with more than two utility poles per consumer), the more the costs increase (more than US $\$ 1000$ for a distance of less than $1 \mathrm{~km}$ to the grid). For four poles per consumer the cost explodes to more than US $\$ 4000$, justifying the search for alternative methods of generating electricity.

The cost of transmission and distribution of electricity in India has been studied by Nouni et al. ${ }^{9}$ It varies from US $\$ 0.07$ to US $\$ 5.1$ per $\mathrm{kWh}$ depending on the peak electrical load and the load factor. The worst case was for a distance of $20 \mathrm{~km}$ between the village and an existing $11-\mathrm{kV}$ line, a peak load of $5 \mathrm{~kW}$, and a load factor of 0.1 (where electricity would be mainly required for lighting in the evening for a few hours). These villages built on hilly ground have a relatively lower number of households. Moreover, most of them have no industrial or commercial load.

This result clearly indicates that providing electricity through grid connectivity to small remote villages in hilly and other inaccessible areas where people have very low income is financially unviable. Renewable energy technologies such as solar, wind, and thermoelectric generators (TEGs) are costeffective options for these specific off-grid households.

Small TEG prototypes with optimized DC/ DC convertors (Fig. 1) have been studied in our laboratory. These TEGs are one of the solutions for these households far from the power grid. Coupled with clean and efficient cooking stoves developed by Planète Bois (Fig. 2), TEGs can provide electricity in order to improve the combustion and to respond to basic household needs [light-emitting diodes (LEDs), cell phone and radio charging devices]. Planète Bois, a nongovernmental organization, aims to transfer recent knowhow in biomass combustion and in use of traditional materials (lime, hay, sand, and straw) to promote the use of low-cost and highly efficient stoves for household and small-scale industries, mainly in rural areas.

Figure 2 shows a schematic drawing of the energy-efficient, multifunction, mud stove developed by Planète Bois. The wood in the pyrolysis chamber rests on a bed of embers fed by the entry of primary air at this level. Combustible gases are given off as a result of decomposition by heat (pyrolysis) in the absence of flames and sucked towards a nozzle. Then, these gases are mixed with the oxygen from the secondary air. The flame then breaks out downstream of the injection of secondary air. The smoke extractor fan allows control of the air-to-fuel ratio and therefore optimizes the combustion. The fan also permits the use of a horizontal pipe, avoiding the necessity for long metal flue pipes and building of chimneys. The idea is to put the TEG in a cogeneration system which simultaneously provides electric power and useful heat for hot water. ${ }^{10}$ Measurements made with a $10-\mathrm{kW}$ wood-burning cooking stove developed by Planète Bois showed that about $2.4 \mathrm{~kW}$ is used to heat up domestic hot water. This heat flux from the hot gases to the water will provide the temperature difference through the TE modules.

A prototype TEG (consisting of one or two commercial bismuth telluride modules) has been designed and tested with a gas heater providing a flux similar to the one of the cooking stove. The mechanical and thermal parts of this prototype have already been described. ${ }^{11}$

During combustion, the temperature of the combustion gases varies significantly (fire ignition, wood loading, presence or absence of pans on the hotplate, and quality of wood). Furthermore, the water temperature increases slowly but can vary quickly when the user takes hot water and adds cold water to the tank. For these reasons, the temperature difference fluctuates a lot during use of the stove.

Thermoelectric modules are made of $n$ couples of $p$-type and $n$-type semiconductor pellets connected with metal solder. They can be represented by a voltage source with an internal resistance. The voltage source is approximately proportional to the temperature difference between the two sides of the thermoelectric elements: $E_{\mathrm{oc}}=n \alpha_{p n}\left(T_{\text {hot }}-T_{\text {cold }}\right)$, and the internal resistance $R_{\mathrm{i}}=n\left[\left(\rho_{n} \times L_{n} / S_{n}\right)\right.$ $\left.+\left[\rho_{p} \times L_{p} / S_{p}\right]\right]+R_{\mathrm{c}}$ is also correlated with temperature. $T_{\text {cold }}$ and $T_{\text {hot }}$ are, respectively, the cold- and hot-side temperatures of the TE modules, and $n$ is the number of semiconductor couples.

$L_{n}, L_{p}$ and $S_{n}, S_{p}$ are, respectively, the leg length and cross-sectional area of the pellets. $\rho_{p}$ and $\rho_{n}$ are the resistivity of each material, and $\alpha_{p n}$ is the

\begin{tabular}{|l|lll|}
\hline Journal : 11664_JEM & Dispatch : 22-1-2013 & Pages : $\mathbf{1 2}$ \\
& & $\square$ LE & $\square$ TYPESET \\
& Article No.: 2459 & $\nabla$ CP & $\varnothing$ DISK \\
\hline
\end{tabular}




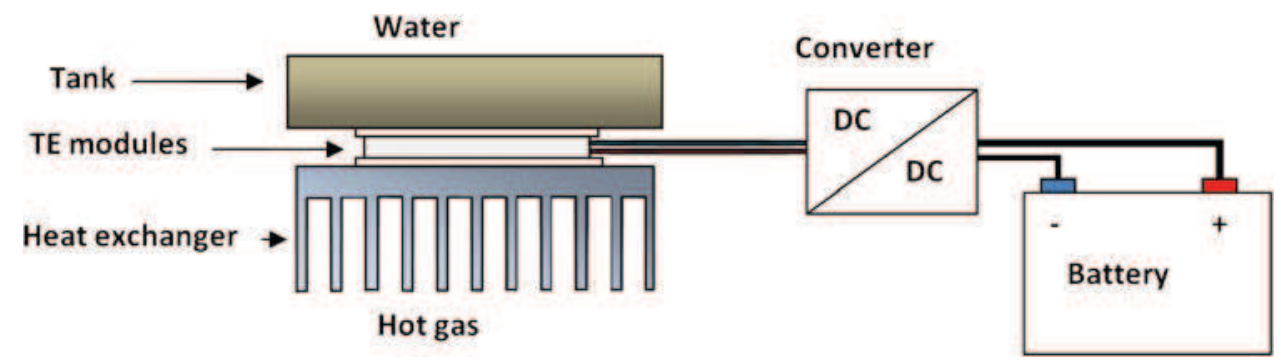

Fig. 1. Prototype TEG with optimized DC/DC convertor, for use with hot gas source and cold water sink.

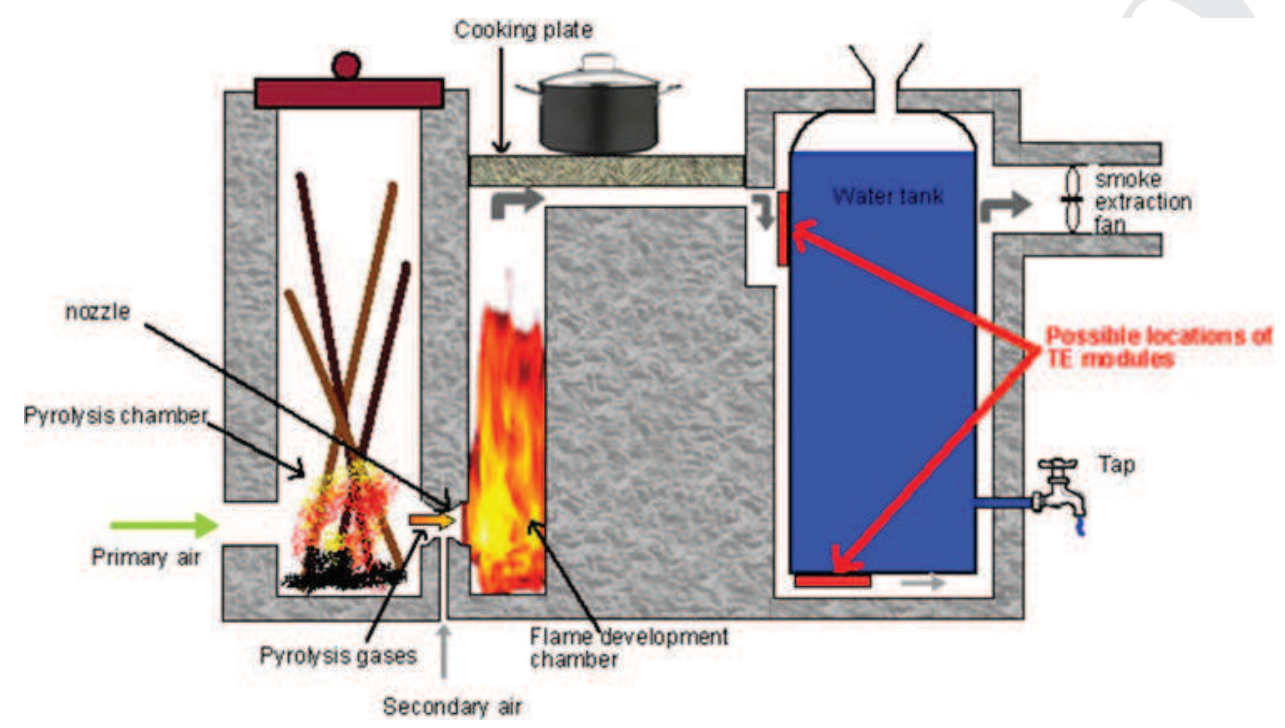

Fig. 2. Planète Bois cooking/water heating stove design.

Seebeck coefficient of the couple; these parameters are temperature dependent. $R_{\text {c }}$ represents all the electrical contact resistances.

Figure 3 shows the variations of the output voltage and of the temperatures for a 1-h experiment based on typical use of the cooking stove.

Because of this huge variation, a DC/DC converter (Fig. 4) is necessary to regulate the voltage and to store electricity in a battery in order to have electricity available all day long, as the TEG only produces when the stove is working. To get the maximum power from the TE modules, the load should be adapted, which means that the impedance seen by the TEG is equal to its internal resistance. As the current in the battery depends on the battery charging but also on the variation of the load, the output current and thus the input current of the DC/DC converter will fluctuate a lot. With a fixed output voltage the load would not be adapted and the efficiency would be low. To be always adapted, the solution is to control a DC/DC converter with a maximum power point tracker (MPPT). This can be done by adding a microcontroller which controls the output power of the converter.

The next section describes the DC/DC controller and the use of the MPPT algorithm. Special attention has been paid to the choice of electronic components in order to increase the internal efficiency of the DC/ DC controller. The MPPT algorithm efficiency has also been studied using a Matlab-Simulink model including measurement noise in order to determine the best tracking increment value (or rather range). The overall electrical efficiency between the output power of the TE module and the power at the battery terminals is presented. The test of the DC/DC controller is presented inthe following section. In the last section, the first experimental results obtained with a hot gas generator simulating the exhaust of the combustion chamber of a cooking stove are shown. The final stored electrical power results are presented, and the energy efficiency between the electrical energy given by the TE modules and the energy storage in the battery is measured. Based on these results, the daily electrical production of the multifunction cooking stove and its possible uses are evaluated.

\section{DC/DC CONVERTER}

The study that was done to maximize the performance of the DC/DC converter is presented in this

\begin{tabular}{|l|lll|}
\hline & Journal : 11664_JEM & Dispatch : 22-1-2013 & Pages : 12 \\
& Article No.: 2459 & $\square$ LE & $\square$ TYPESET \\
& $\square$ CP & $\square$ DISK \\
\hline
\end{tabular}




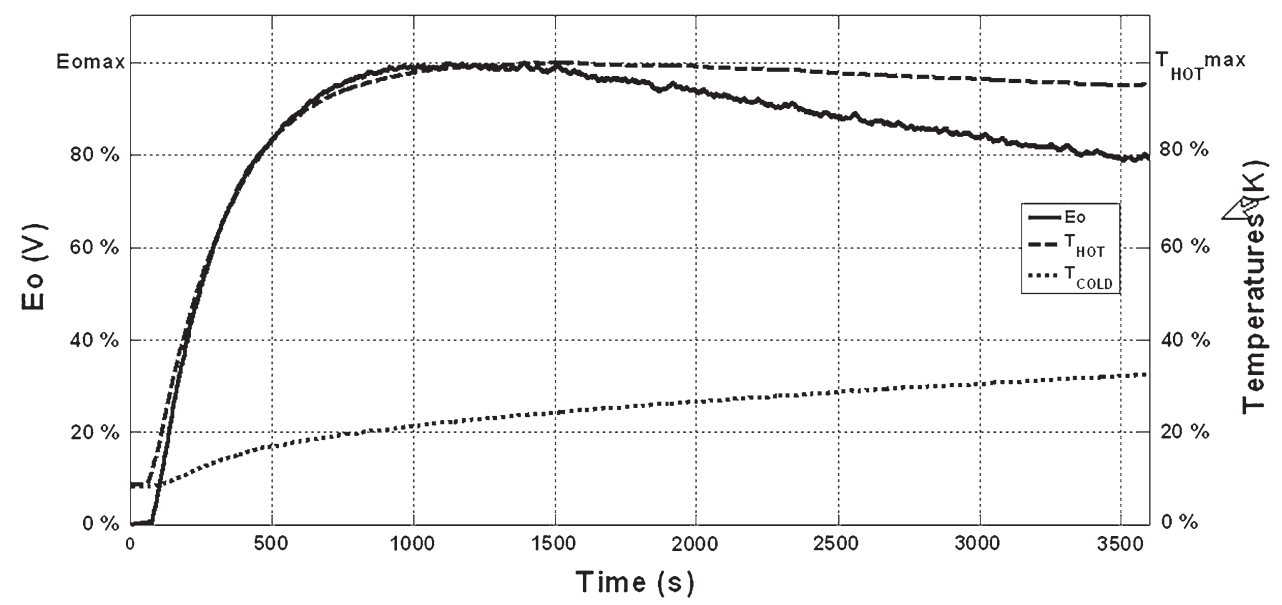

Fig. 3. Typical variations of the output voltage and temperatures of the TEG.

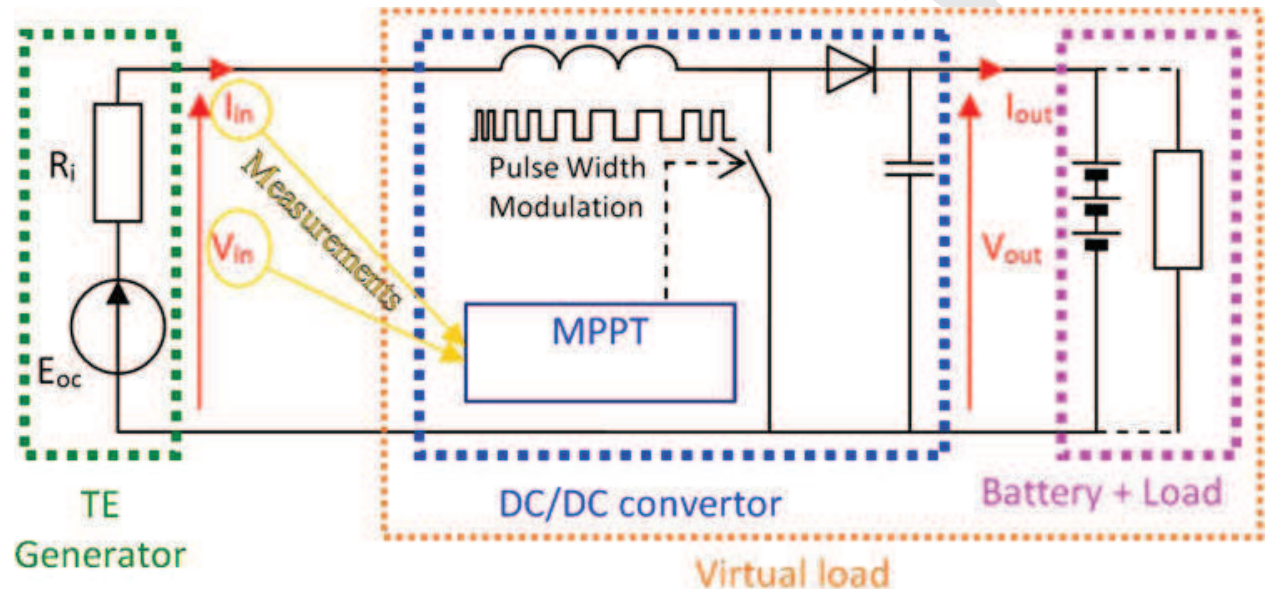

Fig. 4. Global electric circuit of the TEG with its storage battery and load.

section. The power efficiency can be defined as the ratio of the power stored in the battery to the maximum power that the thermoelectric module can provide for a specific operating point. The energy efficiency can be defined as the ratio of the energy stored in the battery to the maximum energy that the thermoelectric module can provide during typical use of the stove. The goal is to optimize energy efficiency.

The design of the converter can be separated into two stages: first the electrical components part which gives us the $\mathrm{DC} / \mathrm{DC}$ efficiency, then the algorithmic part which represents the MPPT efficiency. This study is divided into two stages, because the total efficiency is the result of the following product: Efficiency $=$ MPPT efficiency $\times$

electronic efficiency, which can be studied separately.

For this application, a boost convertor has been used (Fig. 4). $V_{\text {in }}$ and $I_{\text {in }}$ are, respectively, the input voltage and current of the DC/DC convertor. $V_{\text {out }}$ and $I_{\text {out }}$ are, respectively, the output voltage and current of the DC/DC convertor.

\section{Principle of the MPPT}

Description of the MPPT Algorithm

The TE module with the DC/DC converter and the load is illustrated by Fig. 5. The electrical power $\left(P_{\text {in }}\right)$ characteristic of the TE modules as a function of the voltage is plotted in Fig. 6 for several values of the temperature difference between the two sides of the TE modules. These curves, typical of TE modules, show that the voltage $V_{\text {in }}$ must be adapted in order to get the maximum power. The maximum power point (MPP) changes with the temperature difference, which is why a management algorithm is necessary.

The parameter driven by the microcontroller is the duty cycle (Dc) of the pulse width modulation, which is the fraction of the commutation period $T$ during which the switch is on. Assuming an ideal

\begin{tabular}{|l|lll|}
\hline Journal : 11664_JEM & Dispatch : 22-1-2013 & Pages : 12 \\
& Article No.: 2459 & $\square$ LE & $\square$ TYPESET \\
& $\square \mathrm{CP}$ & $\varangle$ DISK \\
\hline
\end{tabular}


converter (without losses) the relations governing the system are:

$$
\begin{aligned}
I_{\text {in }} & =\frac{I_{\text {out }}}{(1-\mathrm{Dc})} \cdots V_{\text {in }}=V_{\text {out }} \times(1-\mathrm{Dc}) \cdots P_{\text {in }} \\
& =V_{\text {in }} \times I_{\text {in }}=V_{\text {out }} \times I_{\text {out }}=P_{\text {out }} .
\end{aligned}
$$

$P_{\text {out }}$ is the electrical power output of the $D C / D C$ converter.

It is reasonable to consider that $V_{\text {out }}$ is fixed by the battery voltage, therefore the choice of Dc imposes the voltage $V_{\text {in }}$ and as a consequence the currents.

A simple MPPT algorithm strategy making $V_{\text {in }}$ equal to $E_{\text {oc }} / 2$ could not be used in this study because $E_{\text {oc }}$ fluctuates a lot with temperature. Another strategy based on tracking the internal resistance is not possible since this internal resistance is also a function of the temperature.

The solution is to measure both $V_{\text {in }}$ and $I_{\text {in }}$ in order to determine the electrical power and to

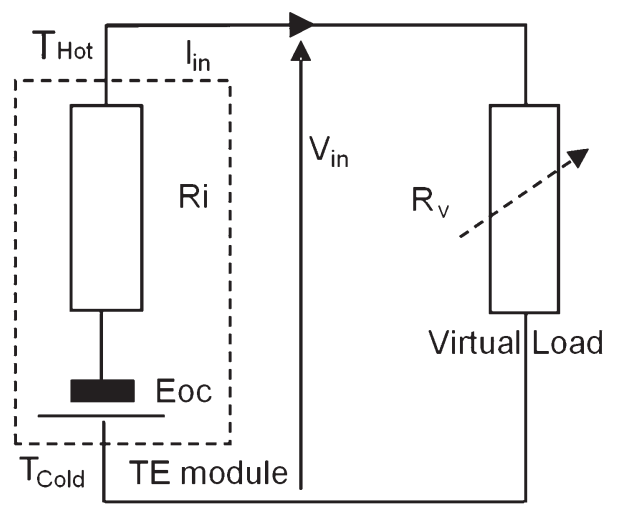

Fig. 5. Electrical model of the TE module and the DC/DC virtual load. adjust Dc in order to maximize this value. The perturb and observe (P\&O) method which maximizes the input power $\left(P_{\text {in }}\right.$, the power generated by the TEG) without any knowledge of the source is chosen for the MPPT. The principle (Fig. 7) is to alter the voltage $V_{\text {in }}$ by a small amplitude (obtained by changing Dc slightly) around its initial value and analyze the behavior of the $P_{\text {in }}$ power variation that results. If a positive increment of the voltage $V_{\text {in }}$ causes an increased power $P_{\text {in }}$, this means that the operating point is on the left of the MPP. If the power decreases, this implies that the system has exceeded the MPP. A similar analysis can be done when the voltage decreases. From these various analyses of the consequences of changing voltage on the characteristic $P_{\text {in }}=f\left(V_{\text {in }}\right)$, it is easy to locate the operating point from the MPP. Then, appropriate control will allow convergence to the maximum power.

The algorithm is described in Fig. 7. The frequency of the algorithm was fixed at $1 \mathrm{~Hz}$ for all the analyses.

$V_{\text {in }}$ and $I_{\text {in }}$ are measured using the analogto-digital converter inputs of the microcontroller. Measurement of $V_{\text {out }}$ is also necessary to incorporate battery protection in order to increase its life expectancy. Moreover, to avoid problems due to noise at low measurement values, we decided that, for input power less than $1 \mathrm{~W}$, the algorithm does not start and the Dc is fixed.

\section{Efficiency Analysis and Optimization}

The principal limitation of the $\mathrm{P} \& \mathrm{O} \operatorname{method}^{13}$ is the oscillations around the maximum power which decrease the MPPT efficiency. The amplitude of these oscillations, which depends on the noise measurements $\left(\Delta I_{\text {in }}\right.$ and $\left.\Delta V_{\text {in }}\right)$ and on the input voltage values, can be minimized by choosing an optimized Dc increment $\Delta \mathrm{Dc}$.

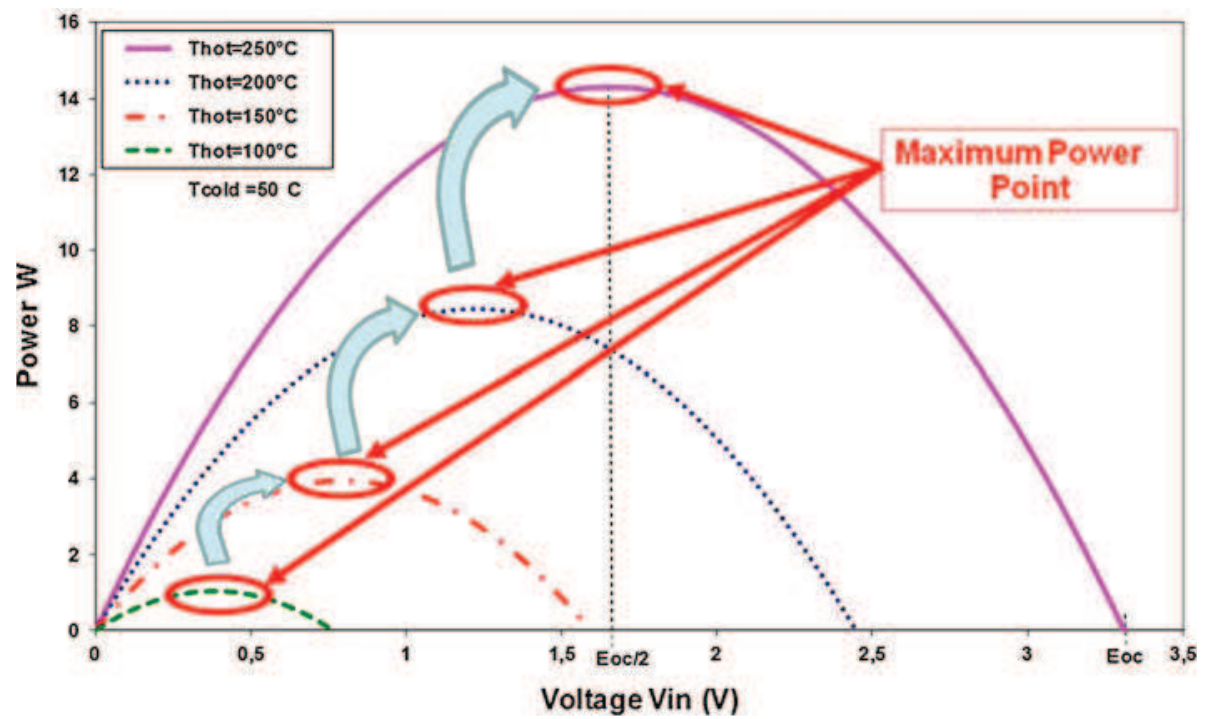

Fig. 6. TE module output power as a function of the TE voltage for different temperatures.

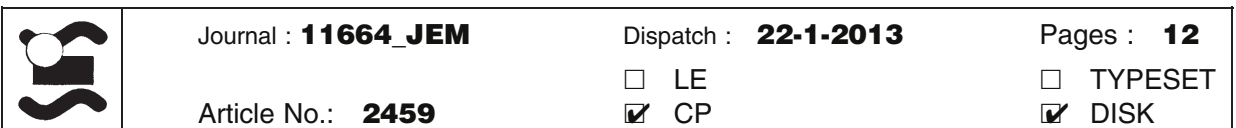



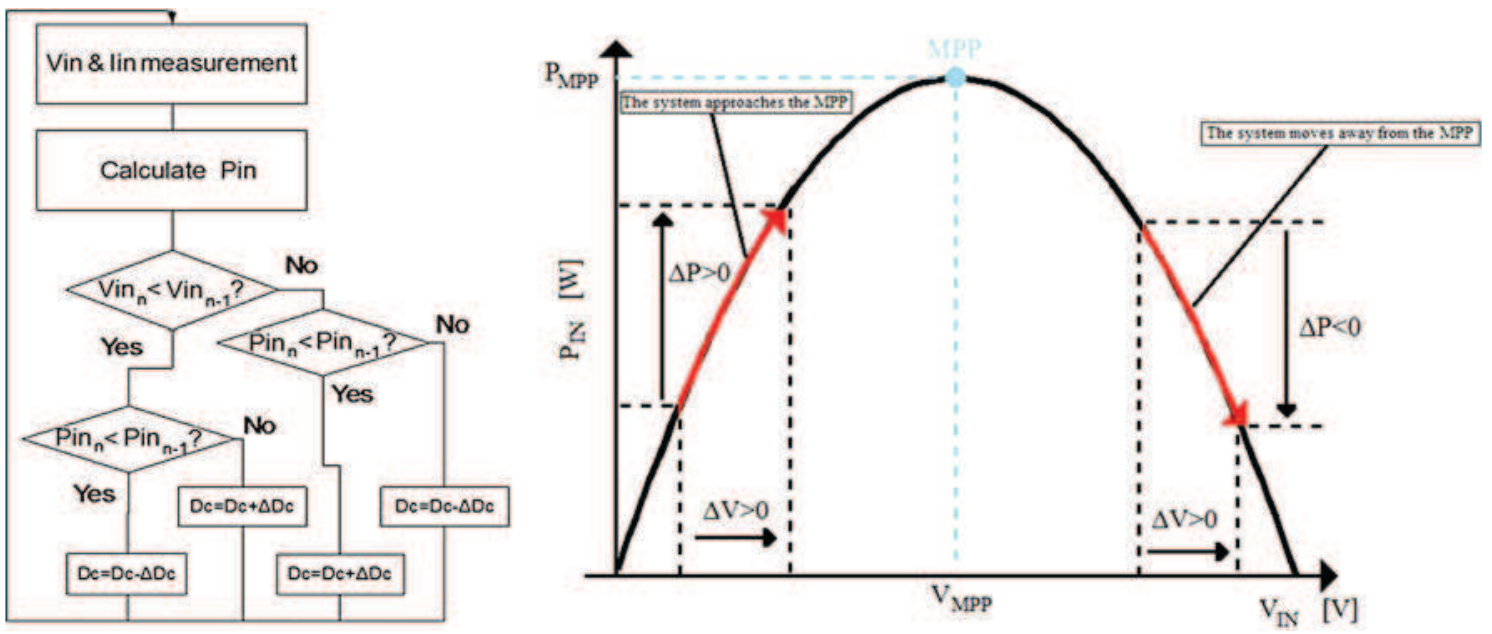

Fig. 7. Principle of MPPT with its algorithm.

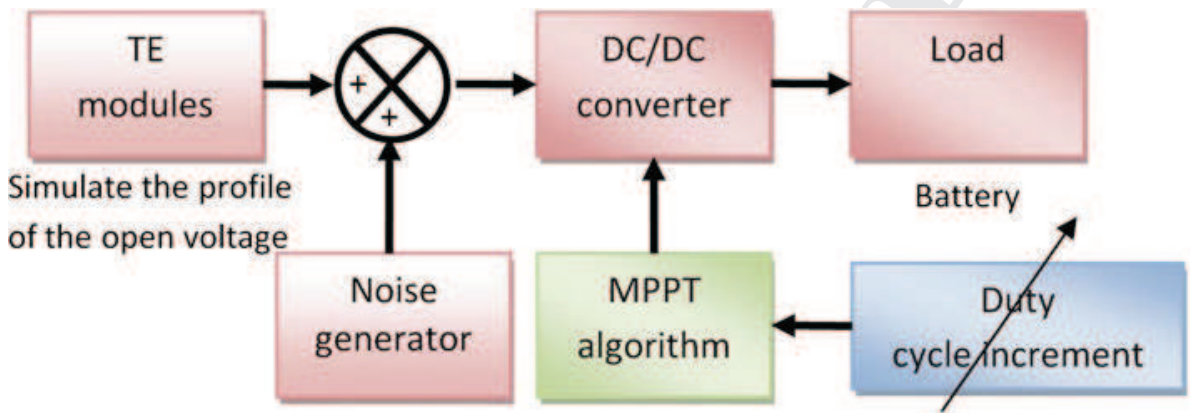

Fig. 8. Simulink model of the TE generator with its load.

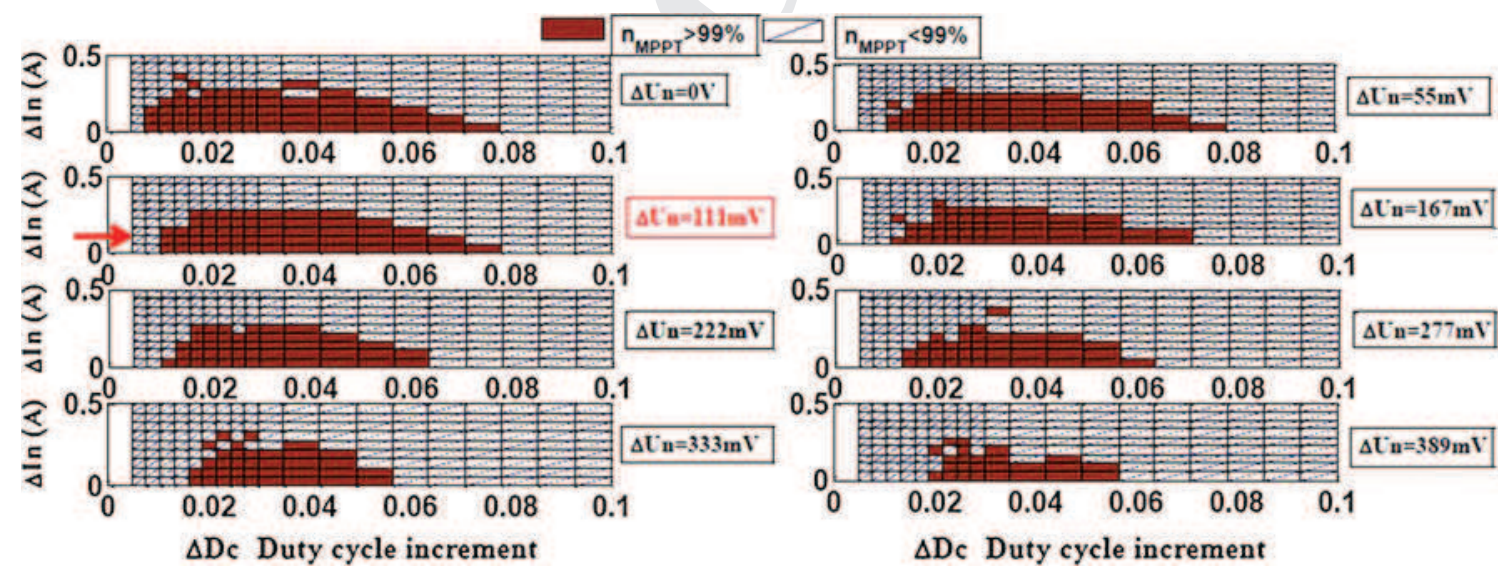

Fig. 9. Influence of noise $\left(\Delta I_{n}\right.$ and $\left.\Delta V_{n}\right)$ on the energy efficiency of the P\&O algorithm.

Two analyses were carried out using a Simulink model (Fig. 8), the first one taking into account the impact of the noise on the current and voltage measurements, and a second analysis taking into account the influence of the maximum open-circuit voltage.

To carry out a realistic analysis, the cycle of Fig. 3 based on typical use of the cooking stove was used for the TE modules block. A noise generator added random noise (white noise) on $V_{\text {in }}$ and $I_{\text {in }}$. A heat cycle of $1 \mathrm{~h}$ is considered. The typical value of the open-circuit voltage reached during the typical cycle $E_{\text {omax }}$ is $9.2 \mathrm{~V}$ (corresponding to $10 \mathrm{~W}$ ), but it was used as a parameter in our study.

The first analysis presents the influence of the Dc increment choice for different noise values on the efficiency. Noise can originate in the environment of the system, but it mainly comes from the DC/DC

\begin{tabular}{|l|lll|}
\hline & Journal : 11664_JEM & Dispatch : 22-1-2013 & Pages : 12 \\
& Article No.: 2459 & $\square$ LE & $\square$ TYPESET \\
& $\square$ CP & $\square$ DISK \\
\hline
\end{tabular}




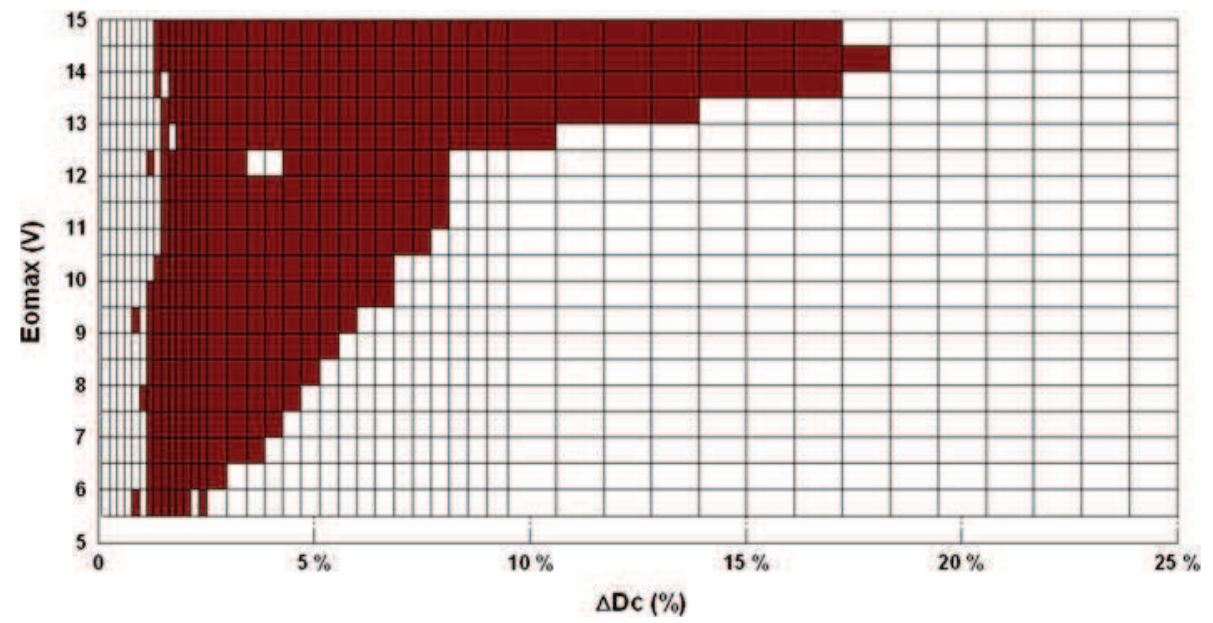

Fig. 10. Influence of the maximum open-circuit voltage on the energy efficiency of the P\&O algorithm for different increments of Dc.

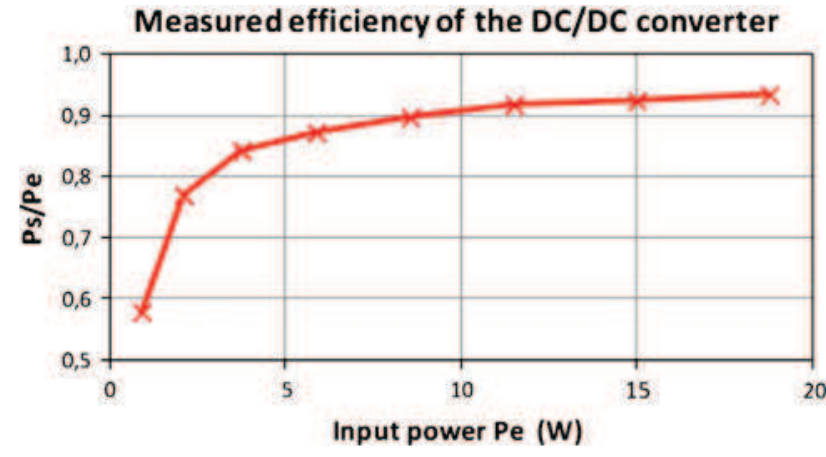

Fig. 11. Electronic power efficiency of the DC/DC converter.

converter. The DC/DC converter works at about $100 \mathrm{kHz}$, and the maximum commuted voltage and current are, respectively, $7 \mathrm{~V}$ and $3 \mathrm{~A}$, so the noise cannot be avoided. The Simulink model was run ten times for each point, and the energy efficiency over the entire cycle was calculated.

$\Delta \mathrm{Dc}$ is a crucial parameter in choosing a trade-off between speed and oscillations. If $\Delta \mathrm{Dc}$ is too small, in case of quick variations of the variables (mainly input voltage and output current), the algorithm is slow to reach the MPP. If $\Delta \mathrm{Dc}$ is too big, the algorithm oscillates two much around the MPP at steady-state operation.

The results presented in Fig. 9 (MPPT efficiency over $99 \%$ is in brown and below $99 \%$ in white) show that the brown area decreases when the noise voltage increases. In the case of unknown noise sources, the Dc increment has to be chosen between $2 \%$ and $5 \%$ in order to maximize efficiency.

The second analysis was performed to evaluate the effects of variation of the maximum open-circuit voltage.

In winter, according to Planète Bois, the hot water needs are more important $(2.5 \mathrm{~kW}$ instead of $1.75 \mathrm{~kW}$ ), so the heat flux increases, and the voltage of the TE modules increases. Moreover, the ageing

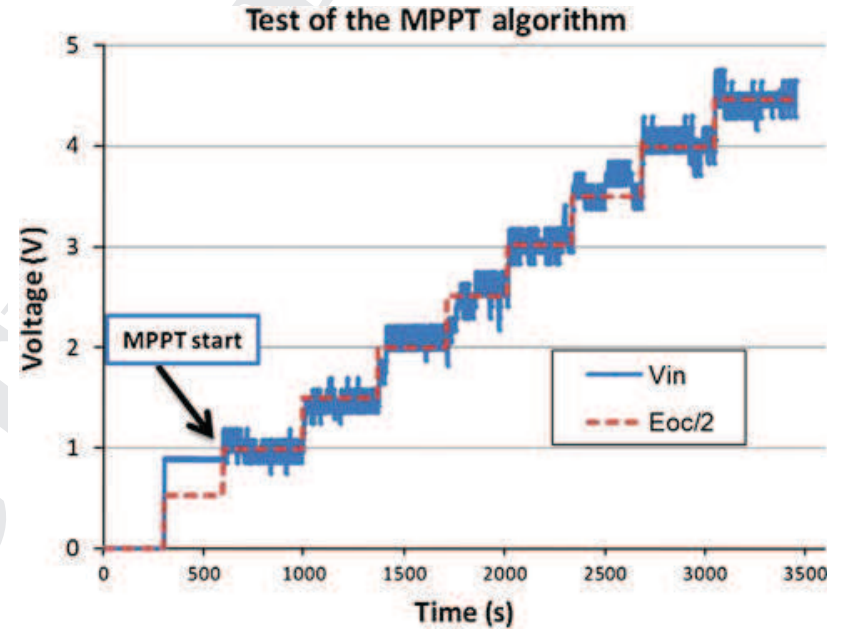

Fig. 12. Test of the $P \& O$ algorithm.

of various materials and the installation of the system may also change the operating point. To study this influence, we chose to keep the same curve shape (Fig. 3) and to vary the maximum value of the open-circuit voltage $E_{\text {omax }}$. This is why an analysis on the impact of the maximum open-voltage was carried out.

In our prototype, the noise is the result of the voltage and current commutations at $100 \mathrm{kHz}$ of the DC/DC convertor. Measurements show that the voltage noise is around $110 \mathrm{mV}$ and that the current noise is around $110 \mathrm{~mA}$ (represented by a red arrow in Fig. 9). It will be the same in isolated houses. The criterion is also to keep the energy efficiency over $99 \%$.

The result of the simulation is presented in Fig. 10, where the MPPT efficiency over 99\% is in brown and below $99 \%$ is in white. $E_{\text {omax }}$ was chosen between $5.5 \mathrm{~V}$ and $14 \mathrm{~V}$, because when $E_{\text {omax }}<5.5 \mathrm{~V}$, the electrical power output is not

\begin{tabular}{|c|c|c|c|c|c|}
\hline \multirow{2}{*}{9} & \multicolumn{2}{|c|}{ Journal : 11664_JEM } & Dispatch : & 22-1-2013 & Pages: 12 \\
\hline & Article No.: & 2459 & $\begin{array}{ll}\square & \mathrm{LE} \\
\nabla & \mathrm{CP}\end{array}$ & & $\begin{array}{ll}\square & \text { TYPESET } \\
\nabla & \text { DISK }\end{array}$ \\
\hline
\end{tabular}




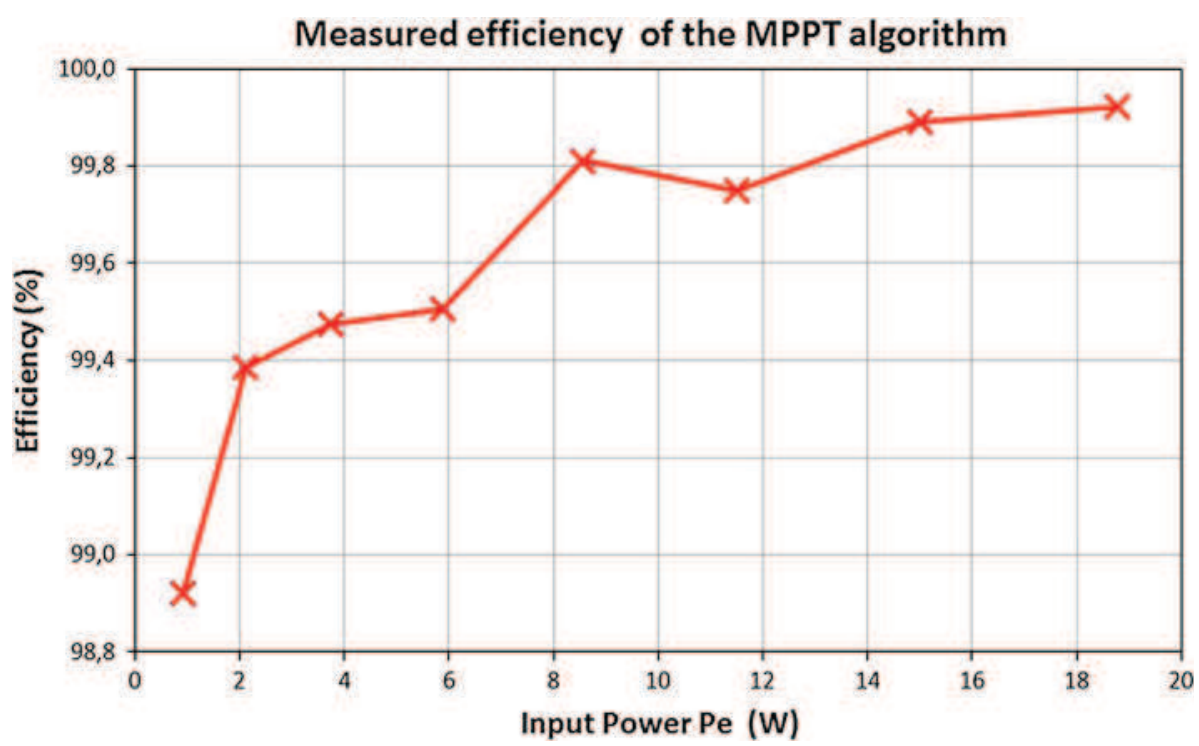

Fig. 13. Measured power efficiency of the P\&O algorithm.

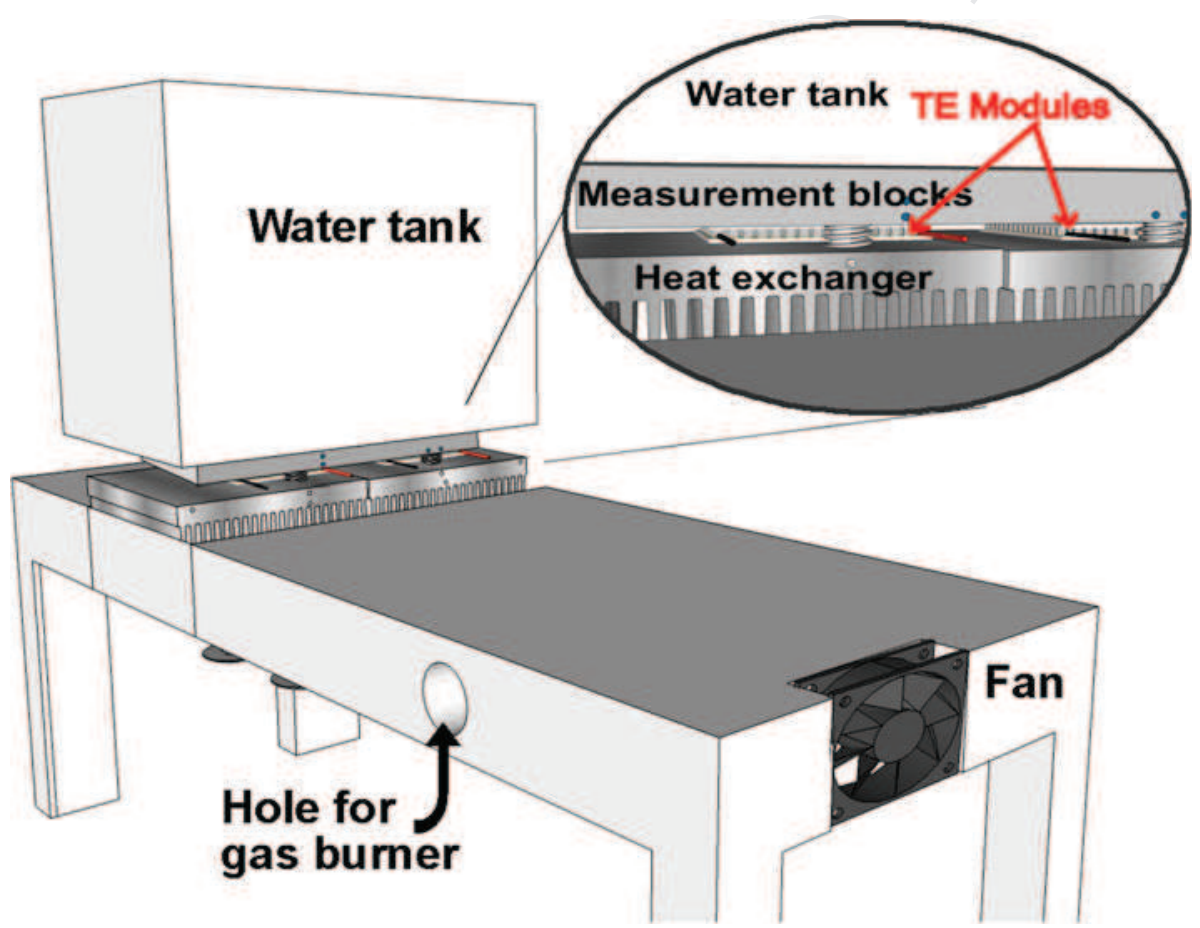

Fig. 14. Test bench for simulating the stove.

significant and because $14 \mathrm{~V}$ is the maximum value for the boost converter.

The figure shows that, when the open-circuit voltage increases, the area of efficiency up to $99 \%$ increases. This is due to the oscillation phenomenon: at low open-circuit voltage, if the Dc increment is too high, oscillations cause significant losses, whereas at high open-circuit voltage, even if increasing the Dc increment increases the oscillation losses, $99 \%$ is maintained.
Figure 10 clearly demonstrates that the optimal value for the increment of Dc is around $2 \%$, and the large area of the graph with acceptable values shows that this value is not critical.

MPPT Conclusion

A MPP boost converter dedicated to the TEG has been developed. The model-based design of the DC/ DC converter, including modeling of noise and using

\begin{tabular}{|l|lll|}
\hline Journal : 11664_JEM & Dispatch : 22-1-2013 & Pages : 12 \\
& Article No.: 2459 & $\square$ LE & $\square$ TYPESET \\
& $\square$ CP & $\square$ DISK \\
\hline
\end{tabular}




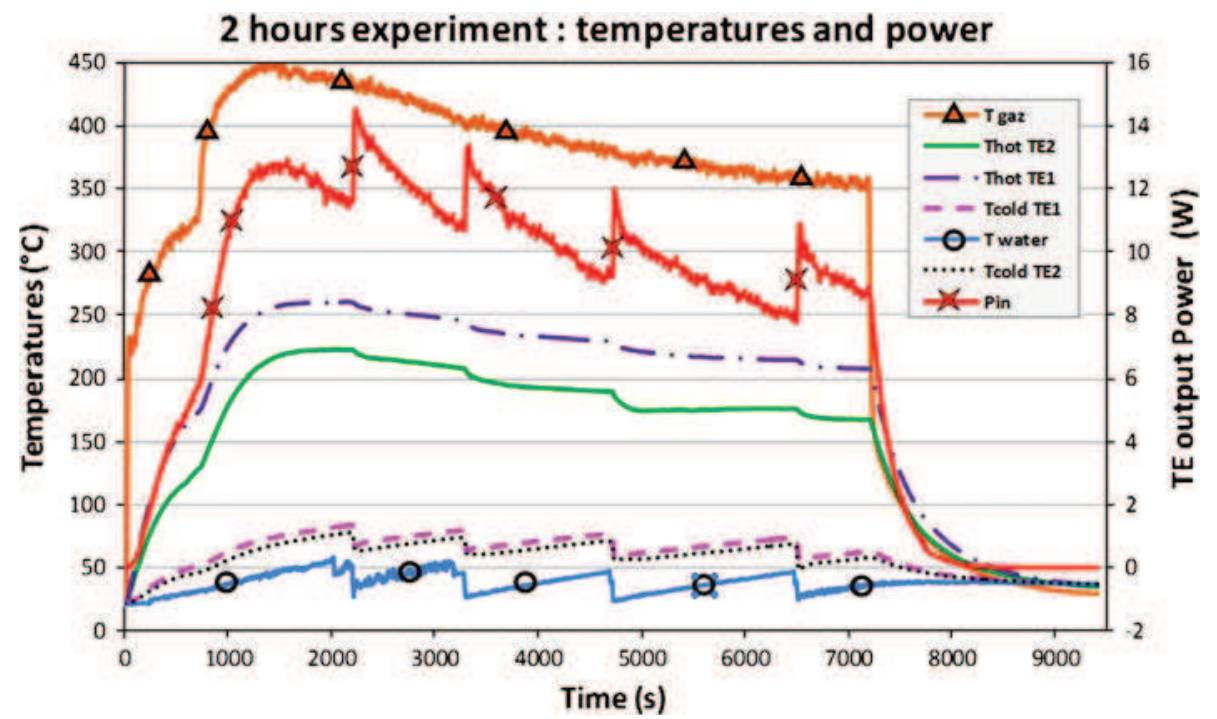

Fig. 15. Temperatures and electrical power of a 2-h experiment of the TEG.

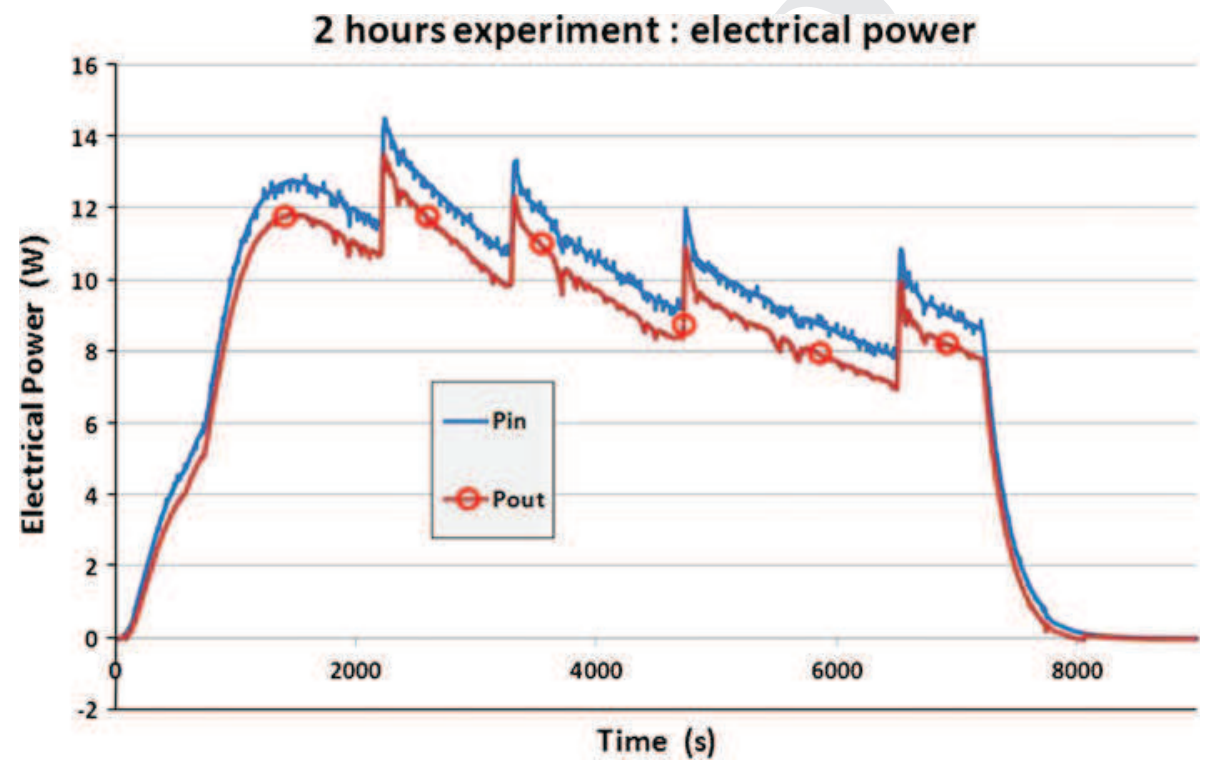

Fig. 16. Input and output electrical power of the DC/DC converter for a 2-h experiment of the TEG.

typical measurements of the output voltage of the TE generator as inputs, allows the choice of an optimal value for the increment of Dc. The design shows that, in the case of unknown noise sources, the Dc increment has to be chosen between $2 \%$ and $5 \%$ to maximize the energy efficiency. When the TEG is used in the Planète Bois cooking stove in an isolated house, noise will come from the commutation of the converter and will be known. In this case, a choice of $2 \%$ will optimize the converter for all the various operating conditions of the stove. With this choice of $2 \%$ for the Dc increment and with the actual thermal cycle, calculations show that we can expect a MPPT efficiency of $99.5 \%$.

\section{Test of the DC/DC Converter}

A DC/DC converter driven by an MC9SO8 microcontroller was built and tested. The electronic components were chosen in order to have good conversion efficiency. The electronic efficiency of the DC/DC boost convertor was tested for different power input values (Fig. 11).

The power efficiency within the normal operating range is better than $90 \%$. This efficiency is limited by the technology of the components and therefore mainly by price.

The MPPT algorithm was installed in the microcontroller. To avoid problems at very low voltages

\begin{tabular}{|l|lll|}
\hline Journal : 11664_JEM & Dispatch : 22-1-2013 & Pages : 12 \\
& Article No.: 2459 & $\square$ LE & $\square$ TYPESET \\
& $\square$ CP & $\square$ DISK \\
\hline
\end{tabular}




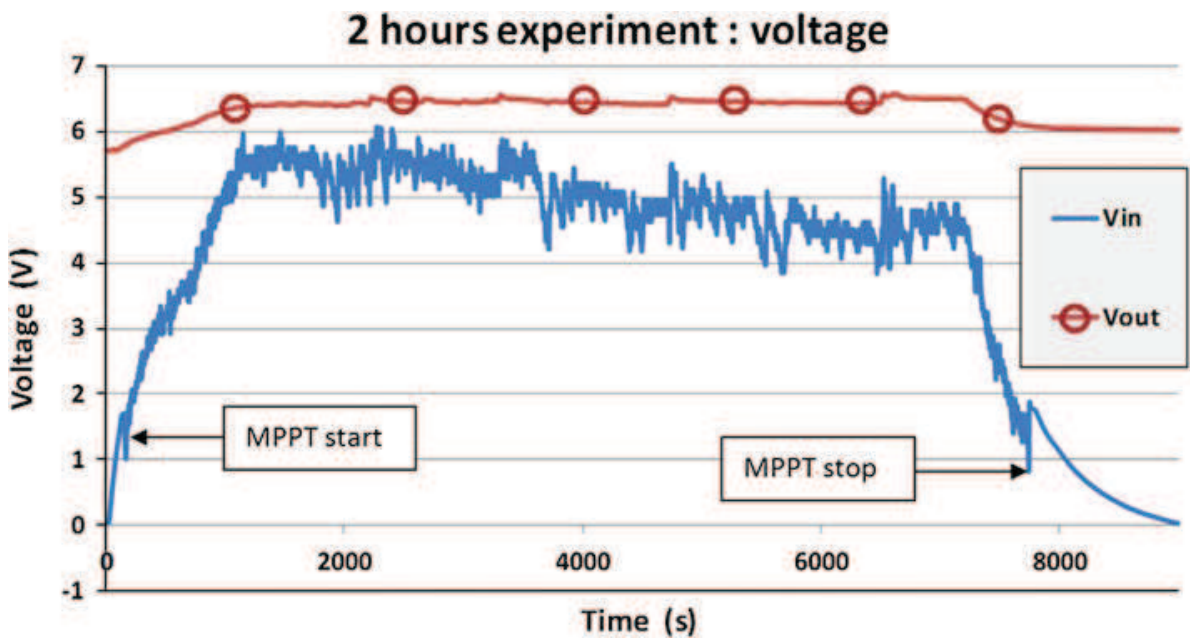

Fig. 17. Input and output voltage of the DC/DC converter for a 2-h experiment of the TEG.

Table I. Electrical energy produced and its possible uses for different cooking cycles

\begin{tabular}{lccc}
\hline Cycle & One Cooking $(2 \mathrm{~h})$ & Two Cookings per Day & Two Cookings (One Long) per Day \\
Electrical energy stored $(\mathrm{Wh})$ & 18.2 & 36.5 & 54.7 \\
Use example* & $\begin{array}{c}\text { Fan, one phone charge, } \\
\text { and } 3 \mathrm{~h} \text { of light }\end{array}$ & $\begin{array}{c}\text { Fan, two phone charges, } \\
\text { and about } 6 \mathrm{~h} \text { of light }\end{array}$ & $\begin{array}{c}\text { Fan, two phone charges, } \\
\text { and about 10 h of light }\end{array}$ \\
\hline
\end{tabular}

* Phone battery of $3.7 \mathrm{~V}, 1050 \mathrm{mAh}$. Light consumption of $4 \mathrm{~W}$. Fan $1 \mathrm{~W}$ during cooking.

Table II. Economic study of the TEG

\begin{tabular}{lccc}
\hline Number of systems & $<5$ & $<100$ & $<1000$ \\
Price $(€)$ & 200 & 120 & 70 \\
\hline
\end{tabular}

and currents (mostly because of false measurements due to noise), conditions on the voltage and power level were added to the algorithm. A sleep mode was also added so that there would be no consumption of electrical energy when the TEG is not in use.

The MPPT algorithm was tested using a voltage source $E_{\text {oc }}$ with very low internal resistance. For this reason, a fictitious internal resistance with a value equivalent to the TE module resistance had to be added. Figure 12 shows the evolution of the input voltage of the converter when the open-circuit voltage of the generator was increased in steps. It shows the fluctuations due to the $\mathrm{P} \& \mathrm{O}$ algorithm around the adapted voltage $\left(E_{\mathrm{oc}} / 2\right)$.

The power efficiency of the MPPT algorithm was calculated by comparing the measured output power of the converter with the power obtained in the case where the load is perfectly adapted $\left(E_{\mathrm{oc}}^{2} / 4 R_{\mathrm{i}}\right)$. The results presented in Fig. 13 show that the goal of energy efficiency above $99 \%$ is reached as soon as the input power is significant.

The power consumption in sleep mode was also measured and found to be less than $30 \mathrm{~mW}$.
The next step was to test the energy efficiency of the convertor using a typical cycle of the stove.

\section{TRIAL OF THE COMPLETE TE GENERATOR}

The next step was to test the TE generator with the MPPT DC/DC converter on the prototype TEGBioS (Fig. 1) already described. ${ }^{11}$ The two thermoelectric modules $\left(\mathrm{Bi}_{2} \mathrm{Te}_{3}\right.$ modules from Thermonamic, reference TEP1-12656-0.6) were connected in series, and pressure of 5 bar was applied to ensure good thermal and electric contacts. Electricity was stored in a $6-\mathrm{V}$ battery. Laboratory testing of the generator was performed using a gas burner, as the installation of a wood stove is not possible in the laboratory premises. A small gas (butane) tank supplies the burner.

The smoke duct which heats the hot water in the cooking stove was replaced by a thermally insulated metal pipe. Heat was generated by a $3-\mathrm{kW}$ gas burner, and the hot gases were blown into the pipe right under the TEG by a fan.

Figure 14 shows a schematic diagram of the test bench used to test the whole system. The fan was set to achieve a gas speed in the duct similar to that of the combustion gases from a cooking stove. The heat source was a moving airstream at about $400^{\circ} \mathrm{C}$, and the cold source was a water tank of $9 \mathrm{~L}$. Glass wool (not shown in the schematic diagram) was used as thermal insulation.

\begin{tabular}{|l|lll|}
\hline Journal : 11664_JEM & Dispatch : 22-1-2013 & Pages : 12 \\
& Article No.: 2459 & $\square$ LE & $\square$ TYPESET \\
& $\square$ CP & $\square$ DISK \\
\hline
\end{tabular}


Temperature, voltage, and current were recorded by using an Agilent 34970A data logger. The measurement system gave precision of $\pm 0.01 \%$ for the voltage, $\pm 0.1 \%$ for the current, and $\pm 0.5^{\circ} \mathrm{C}$ for the temperature.

A typical 2-h cooking experiment was carried out. The test protocol respected the traditional use of the cooking stove. The hot water tank was emptied as soon as its temperature reached $50^{\circ} \mathrm{C}$, being refilled with cold water. This was done four times during the cooking. The results are presented in Fig. 15.

The temperatures ThotTE1, ThotTE2, TcoldTE1, and TcoldTE2 were measured on the heat exchangers near the hot and cold sides of the two TE modules. The difference between the two modules is due to the slight asymmetry of the burner. The temperature of the gas was measured just before the heat exchanger in the middle of the hot gas flow. The plotted temperature of the water was measured at the bottom of the tank (it was measured to be $5 \mathrm{~K}$ to $7 \mathrm{~K}$ less at the top, but this is not plotted).

The temperature of the gas decreased slowly because of the decrease in the butane flow in the burner (reduction in pressure in the cylinder of butane gas during the experiment), but the experiment is still representative of a cooking period.

The power generated by the two TE modules $\left(P_{\text {in }}\right)$ and also the power output $\left(P_{\text {out }}\right)$ of the DC/DC convector are plotted in Fig. 16. Peak power occurs immediately after changing the water in the tank. Fluctuations in power due to the algorithm and noise are visible in the figure as expected from the simulation. The maximum power reaches about 14.5 W on the input side of the converter.

Figure 17 shows the startup of the MPPT algorithm. The converter works at a constant Dc until $1 \mathrm{~W}$ is reached. At this time, the input voltage decreases quickly to $E_{\mathrm{oc}} / 2$ and then follows this value, which increases with the temperature difference. After the end of the combustion cycle, the MPPT stops at the same value and then the DC/DC controller goes into sleep mode.

The measurements shown in Fig. 16 allow calculation of the energy produced by the TE modules and stored in the battery by integrating the curve. Then, the electronic energy efficiency of the DC/DC convertor can be calculated and was found to be equal to $90.7 \%$.

Multiplying this efficiency by the efficiency of Fig. 13 we obtain the global energy efficiency of the DC/DC converter, which is around $90 \%$.

It is also possible to evaluate the efficiency of the thermoelectric modules by measuring the heat transmitted to the water during the experiment. Assuming that the heat converted to electrical power is negligible, and if we neglect the losses around the water tank, this heat is the energy entering the TE modules. An efficiency of $2 \%$ was measured. This efficiency is low, but one must keep in mind that the energy that flows through the generator is not wasted because it is used to heat water in the tank.
From this experiment, it is possible to predict the electrical energy produced each day depending on the lifestyle of the inhabitants. Cooking techniques vary widely across the world; for example, simmering lasts far longer than grilling. Two lifestyles were considered: 1 day including two short cooking periods of $2 \mathrm{~h}$, one in the morning and one in the afternoon, and 1 day including one short cooking period in the morning and a 4-h cooking period in the afternoon (representing the preparation of a dish such as a tajine in rural Morocco, for example). The nature of the cooking style has little influence on the operation of the stove. The heat radiated by the cooking plate is very important, and the effect of adding a pan does not really modify the production of hot water and therefore the production of electricity. Time is the main parameter for electricity generation.

The use of the produced electrical energy was then distributed in the following manner over a period of $24 \mathrm{~h}$ : circuit power consumption in sleep mode $(30 \mathrm{~mW})$ outside the period of cooking, consumption of the fan ( $1 \mathrm{~W})$ during cooking times, one or two charges of a mobile phone, and the rest in light with 4-W LEDs. The results are presented in Table I.

As this TEG is for people with low income, these results were completed with an economic study as presented in Table II; the price includes the cost of the TE modules, the heat exchanger, and the DC/DC converter. The price decreases mostly with the number of units, due to the reduction in price of the TE modules when they are bought in large quantities.

The promising results of Table I combined with the reasonable cost in Table II show that the use of TE modules on cooking stoves should enable people living in isolated houses to have light for several hours in the evening and to charge their phones. Of course it also permits the use of improved cooking stoves with a fan, allowing almost perfect combustion. TEGs are a potentially important contributor to the supply of electricity to rural areas.

\section{CONCLUSIONS}

In this paper, optimization of the electric part of a TEG designed for cogeneration in efficient cooking stoves has been presented. The DC/DC converter uses a P\&O MPPT algorithm in order to always match the load to the fluctuating characteristics of the TE modules due to the temperature variation. A model-based design of the DC/DC converter was conducted to determine the increment of Dc of the MPPT algorithm that optimizes the energy efficiency of the converter. With the optimized increment, the MPPT algorithm shows energy efficiency over 99\%, which gives global energy efficiency for the electrical convertor of over $90 \%$. A first experiment made with a hot gas generator simulating the exhaust of the combustion chamber inside a cooking stove allowed the evaluation of the potential of this

\begin{tabular}{|l|lll|}
\hline Journal : 11664_JEM & Dispatch : 22-1-2013 & Pages : 12 \\
& Article No.: 2459 & $\square \quad$ LE & $\square$ TYPESET \\
\hline
\end{tabular}


603 system. This TEG is certainly a low-cost solution for 604 houses that are far from the electrical power grid in 605 developing countries. This TEG has been developed 606 to be combined with a stove designed by Planète 607 Bois; however, it can be easily adapted to be used in 608 stoves that have a hot water tank. Its use is not 609 limited to developing countries but could also be 610 adapted to make autonomous high-technology 611 stoves requiring some electronic control.

\section{ACKNOWLEDGEMENTS}

The authors acknowledge the financial support of the Conseil Régional d'Aquitaine and of the Conseil Général des Pyrénées Atlantiques.

\section{REFERENCES}

1. World Energy Outlook WEO-2010, Energy poverty-how to make modern energy access universal? (Paris: International Energy Agency Publications, 2010). http://www.iea.org/ publications/freepublications/publication/weo2010_poverty. pdf.

2. World Energy Outlook WEO-2007 (Paris: International Energy Agency Publications, 2007), Chap 20, ISBN: 978-92 64-02730-5.
3. A.N. Anozie, A.R. Bakare, J.A. Sonibare, and T.O. Oyebisi, Energy 32, 1283 (2007)

4. J. Parikh, K. Balakrishnan, V. Laxmi, and H. Biswas, Energy 26, 949 (2001)

5. A. Haines, K.R. Smith, D. Anderson, P.R. Epstein, A.J. McMichael, I. Roberts, P. Wilkinson, J. Woodcock, and J. Woods, Lancet 370, 1264 (2007).

6. Telecom Regulatory Authority of India, Highlights of Telecom Subscription Data as on 30 June 2011, Press release. http://www.telecomindiaonline.com/highlights-of-telecomsubscription-data-as-on-30th-june-2011.pdf.

7. The World Bank, Brazil background study for a national rural electrification strategy: aiming for universal access energy (Washington, DC: The International Bank for Reconstruction and Development/The World Bank, 2005). http://www.esmap.org/esmap/node/338.

8. M.R. Nouni, S.C. Mullick, and T.C. Kandpal, Renew Sustain Energy Rev 12, 1187 (2008).

9. D. Champier, J.P. Bédécarrats, M. Rivaletto, and F. Strub, Energy 35, 935 (2010)

10. D. Champier, J.P. Bédécarrats, T. Kousksou, M. Rivaletto, F. Strub, and P. Pignolet, Energy 36, 1518 (2011).

11. J.P. Ferrieux and F. Forest, Alimentations à découpage, convertisseurs à résonnance, edt Dunod, ISBN: 2100041371 (2006).

12. C. Cabal (Ph.D. thesis, Université Paul Sabatier, Toulouse IL, 2008)

13. XXXX.
625

\begin{tabular}{|c|c|c|c|c|c|}
\hline \multirow{2}{*}{9} & \multicolumn{2}{|c|}{ Journal : 11664_JEM } & Dispatch : & 22-1-2013 & Pages: 12 \\
\hline & Article No.: & 2459 & $\begin{array}{ll}\square & \mathrm{LE} \\
\nabla & \mathrm{CP}\end{array}$ & & $\begin{array}{ll}\square & \text { TYPESET } \\
\nabla & \text { DISK }\end{array}$ \\
\hline
\end{tabular}

